\title{
JOSÉ DE ALBUQUERQUE, O ESQUECÍVEL: MÉTODO HISTÓRICO E O PIONEIRISMO NA EDUCAÇÃO SEXUAL NO BRASIL
}

\begin{abstract}
Antonio Fontoura ${ }^{1}$
\section{Resumo}

Durante os últimos vinte anos, o trabalho do médico José de Albuquerque frente ao Círculo Brasileiro de Educação Sexual nos anos 1930 e 40 vem sendo festejado, em grande número de trabalhos acadêmicos, como exemplo de cientificidade e racionalismo na difusão de suas ideias sobre educação sexual. Comparando-se as afirmações de Albuquerque a outras fontes históricas do período, objetiva-se demonstrar que muitos dos fundamentos que sustentaram a argumentação, nestes trabalhos, sobre a difusão das ideias de Albuquerque, são fundados em premissas que não correspondem às evidências históricas; e que, por sua vez, tais premissas foram resultado da negligência a princípios fundamentais do método histórico. O trabalho conclui discutindo a real dimensão da influência das ideias de Albuquerque no período.
\end{abstract}

Palavras chave: História da educação sexual. Metodologia histórica. Círculo Brasileiro de Educação Sexual.

\section{JOSÉ DE ALBUQUERQUE, THE FORGETTABLE: HISTORICAL METHOD AND PIONEERING IN SEXUAL EDUCATION IN BRAZIL}

\begin{abstract}
Over the last twenty years, the work of the physician José de Albuquerque in the 1930s and 40s has been celebrated in a large number of scholarly works as an example of scientific and rationalism in the diffusion of his ideas about sex education. Comparing Albuquerque's claims to other historical sources of the period, this article aims to demonstrate that many of the foundations that supported the arguments about Albuquerque's, in those works, as well as the diffusion of Albuquerque's ideas, are based on premises that do not correspond to historical evidence; and that, in turn, such premises were the result of neglect of fundamental principles of the historical method. This paper concludes by discussing the real dimension of the influence of Albuquerque's ideas in the period.
\end{abstract}

Keywords: History of sex education. Historical methodology. Círculo Brasileiro de Educação Sexual. 


\title{
JOSÉ DE ALBUQUERQUE, EL ESQUECIBLE: MÉTODO HISTÓRICO Y EL PIONEIRISMO EN LA EDUCACIÓN SEXUAL EN BRASIL
}

\begin{abstract}
Resumen
Durante los últimos veinte años, la obra del médico José de Albuquerque frente al Círculo Brasileño de Educación Sexual en los años 1930 y 40 viene siendo festejado, en gran número de trabajos académicos, como ejemplo de cientificidad y racionalismo en la difusión de sus ideas de sobre educación sexual. En comparación con las afirmaciones de Albuquerque a otras fuentes históricas del período, se pretende demostrar que muchos de los fundamentos que sostuvieron la argumentación en estos trabajos sobre la difusión de las ideas de Albuquerque, son fundados en premisas que no corresponden a las evidencias históricas; y que, a su vez, tales premisas fueron resultado de la negligencia a principios fundamentales del método histórico. El trabajo concluye discutiendo la real dimensión de la influencia de las ideas de Albuquerque en el período.
\end{abstract}

Palabras clave: Historia de la educación sexual. Metodología histórica. Círculo Brasileiro de Educação Sexual.

\section{INTRODUÇÃO}

Em 2016, a editora Fiocruz lançou Meu encontro com os outros, obra que busca recuperar as ideias de José de Albuquerque (1904-1984), médico carioca que dedicou parte de sua vida profissional a discutir e divulgar projetos ligados à educação sexual. Descrito na capa como "pioneiro da sexologia no Brasil", o trabalho mais conhecido de Albuquerque liga-se às atividades do Círculo Brasileiro de Educação Sexual (CBES), fundado por ele em 1933 com a intenção, segundo suas palavras, de criar “[...] uma instituição que propagasse entre o povo brasileiro os conhecimentos básicos da educação sexual.” (ALBUQUERQUE, 1958, p. 11).

O texto de divulgação escrito pela editora não é econômico nos elogios a Albuquerque. Apresentado como inovador e racionalista, ele é descrito como um guerreiro em luta pelo direito à educação sexual, em uma sociedade retrógrada, conservadora e moralista:

\footnotetext{
Começava, então, a batalha de José de Albuquerque [...], exímio divulgador de suas ideias. Criou o Jornal de Andrologia, que chegou a ser editado em cinco idiomas. Fundou o Círculo Brasileiro de Educação Sexual e seu Boletim de Educação Sexual [...] alcançou a tiragem de 100 mil exemplares. [...] O rádio também foi bastante utilizado para propagandear as ideias de José de Albuquerque. (MARQUES, 2016).
}

Este trecho repercute o que vem sendo escrito a respeito de José de Albuquerque e do Círculo Brasileiro de Educação Sexual há aproximadamente duas décadas. De certa 
forma, Meu encontro com os outros, organizado pelos antropólogos Sérgio Carrara e Marcos Carvalho, é o ponto culminante de um gradual processo de construção da imagem de um campeão da educação sexual, cujas ações teriam causado tal "[...] rebuliço na elite carioca nos anos 1930" (MARQUES, 2016) que, como afirmou um resenhista, “[...] impressiona [...] o fato de José Albuquerque ter ficado no esquecimento por décadas." (GOMES, 2017).

$\mathrm{E}$, de fato, esse esquecimento parece pedir uma explicação: fundador do Círculo Brasileiro de Educação Sexual, criador do Boletim de Educação Sexual com 100 mil exemplares distribuídos mensalmente, articulista semanal em uma rede de cerca de 750 jornais, promotor do conhecimento sexual em contínuos programas de rádio, membro da Societé de Sexologie de Paris desde 1936 e nome de projeção da sexologia mundial, editor do Jornal de Andrologia enviado regularmente a 18 mil médicos brasileiros, defensor da igualdade de educação sexual para homens e mulheres e contrário à abstinência sexual, curador de uma pinacoteca de educação sexual: como não constatar, mesmo diante deste currículo resumido, que estamos diante de um racionalista que, procurando discutir a questão sexual de um ponto de vista científico, acabou por construir um "[...] forte papel político" (MIKOS, 2017, p. 25) sobretudo por conta de sua influência midiática? “[...] Albuquerque sempre foi um visionário à frente de seu tempo" (AUGUSTO, 2015, p. 38), "[...] um paladino da intervenção educativa" (CARRARA, 1996, p. 263), “[...] considerado pela historiografia como um importante personagem do debate nacional sobre a importância da educação sexual" (FELICIO, 2012, p. 6), que levou "[...] para as questões sexuais uma naturalidade em meio a uma sociedade burguesa formada sob os preceitos e preconceitos religiosos.” (REIS, 2006, p. 86).

Porém, o que parece faltar neste quadro, que começou a ser construído há cerca de 20 anos, é método histórico. Já no século XIX, o historiador francês Charles Seignobos ensinava em sua obra Introdução aos estudos históricos:

\footnotetext{
O que um autor expressa não é sempre o que ele acreditava, porque pode ter mentido; o que acreditava não é necessariamente o que aconteceu, pois pode ter sido enganado. Essas proposições são óbvias. E, no entanto, um primeiro impulso natural nos leva a aceitar como verdadeiras todas as afirmações contidas em um documento [...]; e esta espontânea credulidade deve estar muito arraigada, posto que nos proporciona inúmeros exemplos de erros. (LANGLOIS; SEIGNOBOS, 2014, tradução nossa).
}

A julgar pelas pesquisas em história da educação sexual que abordam o trabalho de José de Albuquerque, não foram poucos os pesquisadores que parecem ter sido enganados por seu primeiro impulso natural, e aceitado praticamente todas as informações que lhes caíram às mãos. Porém autores de documentos históricos mentem ou se enganam: porque estão mal informados, porque não entenderam o que ocorria ou, mesmo, porque teriam a ganhar com a mentira. (LANGLOIS; SEIGNOBOS, 2014). 
Este artigo tem como objetivo evidenciar que muitas das ações e conquistas reivindicadas por José de Albuquerque, aceitas pela maioria absoluta dos pesquisadores em história da educação sexual, estão em desacordo com as evidências históricas. Pretende demonstrar que a tiragem do Boletim de Educação Sexual sequer se aproximava aos 100 mil exemplares mensais, que seu Jornal de Andrologia jamais enviou exemplares a 18 mil médicos, que Albuquerque nunca participou de um rede de publicação de artigos que englobasse 750 jornais, que suas participações em rádio foram esporádicas; buscará demonstrar que o trabalho de Albuquerque não possuía grande relevância internacional, e que determinadas instituições às quais se dizia vinculado, como a Societé de Sexologie de Paris, foram de pouca expressão e tiveram breve existência. Irá argumentar que a influência de Albuquerque se viu limitada por suas ideias conservadoras e retrógradas sobre sexo, mesmo para a sociedade brasileira dos anos 1930 e 40.

\section{O SURGIMENTO DO FENÔMENO JOSÉ DE ALBUQUERQUE}

O primeiro estudo histórico que parece ter discutido o pensamento de José de Albuquerque foi o de Susan Besse (1983), no qual apresenta citações esparsas especialmente do livro Moral sexual. Apesar da procedência cronológica, a dificuldade de acesso a sua tese, bem como a barreira linguística, parecem ter limitado a difusão de suas conclusões. Assim, é provável que a origem dos mais recentes estudos sobre o CBES e o trabalho de José de Albuquerque esteja em duas obras posteriores, publicadas em datas muito próximas entre si.

A primeira, de 1996, é Tributo a Vênus, de Sérgio Carrara, que analisa a luta contra a sífilis no Brasil dos anos 1940. Em seu texto, Carrara dedica várias páginas a descrever as atividades do Círculo Brasileiro de Educação Sexual. Particularmente, destaca a abrangência do Boletim de Educação Sexual, órgão de divulgação do CBES: “[...] o boletim era distribuído gratuitamente para todo o país, chegando a ter a incrível tiragem de 100 mil exemplares por número." (CARRARA, 1996, p. 265). Carrara destaca também a suposta popularidade dos artigos de Albuquerque pois, “[...] em 1935, já faziam parte do circuito de divulgação 700 jornais distribuídos por todo o território brasileiro." (CARRARA, 1996, p. 257). Uma impressionante capacidade de divulgação que se aliava a uma moderna visão de educação sexual: "José de Albuquerque foi, sem dúvida, o representante mais coerente dos que viam a sexualidade enquanto função fisiológica, tendo como objetivos precípuos, tanto o equilíbrio orgânico, quanto a reprodução da espécie." (CARRARA, 1996, p. 259).

O segundo texto que, junto ao de Carrara, impactou inicialmente os trabalhos acadêmicos sobre José de Albuquerque, parece ter sido o da historiadora Diana Gonçalves Vidal: trata-se de seu artigo Educação Sexual: produção de identidades de gênero na década de 1930, de 1998 (VIDAL, 1998). Discutindo a dificuldade de se construir uma 
pesquisa histórica sobre a educação sexual no Brasil, Vidal cita o caso do CBES, cujo boletim teria tiragens de 50 mil exemplares, estaria filiado a 700 jornais que publicariam quinzenalmente seus artigos e, apesar de Albuquerque ser constantemente atacado por adversários, teria alcançado um impressionante sucesso, com palestras via rádio de 15 minutos por semana. Vidal também destaca a abordagem científica da educação sexual por parte de Albuquerque, cujo objetivo seria (nas palavras dele mesmo, em citação selecionada por Vidal) "[...] fazer com que [o estudante] encare com naturalidade sua função sexual, não lhe emprestando atenção de maior monta do que empresta às demais funções do organismo." (VIDAL, 1998, p. 57).

Pode-se perceber que já se revelam tanto no texto de Carrara quanto no de Vidal duas características que seriam constantemente atribuídas ao pensamento Albuquerque e à influência do CBES: por um lado, sua suposta e impressionante penetração midiática; por outro, a racionalidade modernizante de suas ideias sobre sexo e educação. Os trabalhos acadêmicos seguintes, que constantemente citaram as conclusões de Carrara e Vidal, tenderam a se alinhar a estas concepções.

\section{O BOLETIM DE EDUCAÇÃO SEXUAL E OS 100 MIL EXEMPLARES}

Uma das mais recorrentes afirmações sobre o trabalho de José de Albuquerque, repetida em praticamente todos os estudos históricos que tratam de sua obra ${ }^{2}$, refere-se ao sucesso que teria alcançado o Boletim de Educação Sexual: a publicação oficial do CBES teria "[...] uma tiragem média de cem mil exemplares por edição, impresso em papel linha d'água e submetido a todas as exigências que as leis e regulamentos impunham para a circulação dos grandes órgãos da imprensa." (ALBUQUERQUE, 1958, p. 38).

Uma tiragem impressionante, sem dúvida, que representaria a difusão do pensamento de Albuquerque no território nacional. Porém, de onde parte esse dado? A única fonte para todos os trabalhos é a mesma: o próprio José de Albuquerque. Alguns exemplos serão suficientes: Carrara (1996) extraiu a informação das páginas do Boletim, a mesma dos dados apresentados por Vidal (1998) e Malcher (2007); Ribeiro e Reis (2003), por sua vez, citam como fonte obra de Albuquerque (1958); outros autores, como Felicio (2012), Rohden (2012) ou Silva (2001), baseiam suas informações em alguns desses autores anteriores. Ou seja: todos, direta ou indiretamente, tomam Albuquerque como única fonte de informação. Dado que, aliás, ele parecia repetir com certa frequência. Em 1943, em palestra no Paraná, afirmou que o boletim tinha "[...] tiragem superior a 100 mil exemplares" e era "distribuído a todos os pontos do país", embora alertasse que, à época, estava "[...] por força das circunstâncias da situação, sem editar-se." (EDUCAÇÃO..., 1943, p. 3). 
Discutir a veracidade dessas tiragens não é irrelevante. Muito pelo contrário: será a diferença entre o pensamento de um precursor que, por quaisquer razões, era pouco lido e exerceu restrita influência sobre o tema, de outro com notável penetração nacional e líder midiático cuja força do pensamento se fez repercutir em uma centena de milhar de exemplares a cada nova edição de seu boletim. Mais importante, é a diferença entre o pensamento que não encontrou acolhida na sociedade, de outro que era entusiasticamente lido e, assim, ecoava certas concepções sociais. Qual dos dois temos diante de nós?

Ao que tudo indica, o primeiro.

Inicialmente, devemos ter claro que, na década de 1930, eram poucas as publicações que alcançavam a tiragem declarada por Albuquerque para seu boletim. Noite ilustrada, por exemplo, propagandeava o fato de ser a única revista brasileira com uma tiragem superior a 100 mil exemplares (A NOITE..., 1934, p. 2); o popular Jornal das Moças tinha uma tiragem de 40 mil exemplares (JORNAL..., 1932, p. 2); o jornal A Noite se vangloriava, em 1931, por ser um dos mais populares jornais do Brasil, com tiragens que variavam de 90 a 150 mil exemplares por dia (A PROGRESSÃO..., 1931, p. 1); em 1935, o Jornal da Mulher fez questão de destacar "tiragens que são record no Brasil" em propaganda de página inteira: "Um fato invulgar na nossa imprensa pois, para uma revista, 100 mil exemplares é simplesmente admirável." (MAJESTOSO, 1935, p. 4). Portanto, alcançar tal tiragem era, para época, "admirável" mesmo aos grandes periódicos. Por sua vez, boletins de setores específicos costumavam ter tiragens bem inferiores. $O$ Brasil odontológico, órgão da Associação Central Brasileira de Cirurgiões Dentistas, afirmava ter uma tiragem de pouco mais de seis mil exemplares (PERISSE, 1930, p. 3); a Revista brasileira de contabilidade cerca de quatro mil (JORNAIS..., 1931, p. 8). Tiragens próximas às de publicações de órgãos oficiais: em 1937, panfletos do Ministério da Viação eram impressos com tiragens de dois mil exemplares (PROPAGANDA..., 1937, p. 18), e cartazes de propaganda cívica publicados pelo Ministério da Marinha contavam com sete mil exemplares. (CARTAZES..., 1937, p. 5).

Além disso, não há nada que indique que Albuquerque ou o CBES possuísse recursos para arcar com os custos de impressão para tamanhas tiragens: não apenas o Boletim era gratuito, como também o eram as palestras e os cursos dados por Albuquerque. Uma única fonte de renda identificável era a comercialização de livros do próprio Albuquerque por meio do Boletim. (OS CORRUPTORES, 1934, p. 1) ${ }^{3}$. Porém, mesmo que desconsiderássemos os custos, a distribuição de 100 mil exemplares seria um pesadelo logístico. Um jornal diário possui centros de redistribuição (as bancas) às quais os leitores se dirigem individualmente para adquirir sua cópia. O CBES, como veremos, não possuía nada semelhante: assim, não restava alternativa senão a entrega individual - via correspondência, por exemplo. Além disso, e ignorando-se os custos de envelopes e selos, como teria Albuquerque conseguido montar um banco de dados com nomes e endereços de 100 mil pessoas? ${ }^{4}$ Ou mesmo de "apenas" 30 mil, tiragem declarada de outra de suas 
publicações, o Jornal de Andrologia? (MALCHER, 2007, p. 132). E mesmo que possuísse tal banco de dados, como conseguiria preencher dezenas ou centenas de milhares de envelopes manualmente, com o destinatário de cada um dos assinantes?

O CBES jamais parece ter tido estrutura física, de pessoal ou financeira para arcar com os custos desse nível de tiragem e massiva distribuição. De 1933 a 1939, período de publicação do Boletim, repetiu-se em vários jornais, quase todos do Rio de Janeiro, o seguinte texto:

Este periódico, que será de distribuição gratuita [...] será remetido para qualquer ponto do país, devendo os que se interessar em recebê-lo remeter seus endereços para sua redação, à rua 7 de setembro 207, $1^{\circ}$ andar. (IMPOTÊNCIA..., 1933, p. $6)$.

A redação do Boletim que, por sua vez, seria o escritório do CBES indicado nesse anúncio, nada mais era do que o próprio consultório de Albuquerque, onde desde o início dos anos 30 ele diagnosticava e tratava da "[...] impotência em moços" da 1 às 6 (da tarde, presumivelmente): 7 de setembro 207, $1^{\circ}$ andar. (IMPOTÊNCIA..., 1933, p. 6).

Assim, como atesta o anúncio, o sistema de distribuição do Boletim era bastante amador, algo evidente pela permanência da mesma nota nos jornais por tantos anos: tratava-se de uma simples estratégia de contato por correspondência. Albuquerque enviava exemplares aos jornais, já com a notinha pré-escrita que deveria ser publicada. Lendo o jornal, os leitores descobririam o boletim, acabariam por solicitá-lo por correspondência e, quem sabe, adquiririam os livros, quase todos do próprio Albuquerque, divulgados em companhia dos artigos. Deve-se imaginar que tal sistema de distribuição jamais alcançaria uma tiragem de cem mil cópias.

O caráter fantasioso dos números apresentados por José de Albuquerque fica evidenciado por outro dado. Em 1935 ele afirmou que seu Jornal de Andrologia era "remetido regularmente" a 18 mil médicos em todo país. (MALCHER, 2007, p. 132). Ora, esse número nada mais é do que a quantidade aproximada do total de médicos existentes no Brasil do período (SCHEFFER; BIANCARELLI; CASSENOTE, 2011, p. 16). É no mínimo pouco crível que a totalidade da comunidade médica brasileira recebesse, regulamente, uma cópia do Jornal de Andrologia.

Qual seria, então, a tiragem do boletim? Pelos indícios, não era sequer próxima ao alegado por Albuquerque. Uma publicação que, em toda sua existência, teria distribuído pelo país milhões de cópias deixaria, sem dúvida, vestígios: exemplares em bibliotecas, museus, coleções particulares. Mas não é o que acontece; longe disso. Apenas uma coleção parece existir: na Biblioteca Nacional do Rio de Janeiro ${ }^{5}$, o que é condizente a um material de circulação profundamente restrita. Além disso, durante os anos 1930, o Boletim era citado fundamentalmente por jornais do Rio de Janeiro, o que parece evidenciar a circulação local do material - não compatível com uma distribuição nacional de 100 mil exemplares mensais. Mais ainda: mesmo indiretamente, o próprio Albuquerque se referia 
aos assinantes ${ }^{6}$ de seu Boletim como estando na casa das centenas (PRÊMIO JOSÉ..., 1936, p. 5; PARA..., 1937, p. 11).

A tiragem do Boletim, portanto, deveria ser compatível a uma publicação da qual raras cópias sobreviveram, de escassa divulgação nacional, mantida por uma entidade particular sem permanente fonte recursos ou estrutura de redistribuição de publicações. Assim, deveria muito provavelmente ser menor, inclusive, que os boletins de entidades de classe - que possuiriam recursos mais constantes, além de possíveis espaços de redistribuição. Considerando-se que Albuquerque afirmava serem os assinantes na casa das centenas, e sem dados mais precisos, é possível afirmar ser bastante improvável que a tiragem do Boletim do CBES alcançasse as cinco mil cópias.

\section{O CIRCUITO JORNALÍSTICO DE 750 JORNAIS, A PINACOTECA, E A PARTICIPAÇÃO RADIOFÔNICA DE ALBUQUERQUE}

Outra suposta notável conquista de José de Albuquerque, repetida frequentemente nos estudos sobre o CBES, refere-se ao que ele chamava de circuito jornalístico: uma rede de cerca de 750 jornais nos quais dizia publicar, semanal (EDUCAÇÃO..., 1943, p. 3) ou quinzenalmente (VIDAL, 1998), artigos relativos às ações do CBES. Não é muito difícil contestar tal afirmação: não existiam, no Brasil, 750 jornais nas décadas de 1930 ou 40 . O total deveria girar em torno de um terço dessa quantidade (BARBOSA, 2007). Mais do que isso, pesquisando-se nos jornais da década de 1930 foi possível encontrar publicações de Albuquerque em apenas uma fração desse número: um total de $81 \operatorname{artigos~diferentes~}^{7} \mathrm{em}$ 33 jornais.

Como estes números devem ser analisados? Em primeiro lugar pelo contraste com o reivindicado por José de Albuquerque. Ainda que se deva considerar minhas cifras dentro de uma margem de segurança (certamente devo ter pulado artigos, e com certeza não consultei todos os periódicos existentes no Brasil do período), encontrei 91 publicações de artigos de Albuquerque, quando deveria ter encontrado indícios da existência de 108 mil deles (pelo menos cerca de $144 \operatorname{artigos}^{8}$ publicados em 750 jornais).

A segunda forma de análise desses dados é a partir de uma perspectiva qualitativa. Ainda que 33 jornais seja uma fração dos 750 anunciados, não seria assim um mau número: porém, deve-se atentar que quase metade desse número (16) publicou apenas um artigo de Albuquerque naquela década. Cerca de metade de todas as publicações ficou concentrada em apenas quatro jornais de pouca expressividade nacional e, em alguns casos, mesmo regional ${ }^{9}$.

De toda forma, tais cifras não seriam vergonhosas. $\mathrm{Na}$ verdade, apenas representariam o caráter restrito do impacto das ações do CBES. Assim, fica a pergunta: o que buscava Albuquerque inflando os números de sua produção, bem como das do CBES, 
a tais níveis quase burlescos? Evidência para uma possível interpretação é dada por uma carta publicada em 1934 no jornal A Reforma, do Acre. Trata-se do anúncio da fundação do CBES, acompanhado de um convite para que o jornal participasse de seu Círculo (posteriormente Circuito) Jornalístico:

Seu ilustre Presidente, Dr. José de Albuquerque [...] concebeu a organização de um "Círculo Jornalístico", constituído de 300 (1) jornais brasileiros. [...] Sendo o jornal que V. S. tão proficientemente dirige, um dos órgãos de real conceito e projeção no cenário da imprensa brasileiro, tivemos a boa lembrança de incluí-lo no nosso "Círculo Jornalístico", que, estamos certos, não se negará a fazer parte.

(1) Este número atualmente eleva-se a 780. (CÍRCULO..., 1934, p. 4).

A carta é datada de 2 de dezembro de 1933, embora tenha sido publicada apenas em 25 de fevereiro do ano seguinte. É bastante curioso que apresente um círculo contendo inicialmente 300 jornais para, no próprio texto, corrigir-se elevando este número para $780^{10}$. Aumentar de maneira tão absurda algo que já era, a princípio, exagerado, parece ter sido uma estratégia de convencimento: objetivava-se impressionar os editores, de modo a se sentirem envaidecidos pelo convite e tentados a fazer parte de um projeto que, naquele momento, já se apresentaria grandioso.

A carta é assinada por duas pessoas: "Amando F. Peixoto" e "Manoel M. da Silva", ambas ocupando o cargo de "Secretário do Comitê de Imprensa". Há um problema: havia, ao que parece, três "Armandos" na composição do CBES à época, e nenhum deles era "Peixoto" ou fazia parte da comissão de imprensa; havia, por sua vez, um "Manoel" na comissão de imprensa, mas seu sobrenome era "Lavrador", e não "M. da Silva"11 (ALMANAK LAEMMERT, 1934, p. 320-321; CÍRCULO..., 1933, p. 5). Teria sido o próprio Albuquerque o redator dessa carta? A hipótese faz sentido, considerando-se que está de acordo com outras práticas de inflação de atuações e conquistas do CBES.

Essa estratégia do exagero foi uma constante nas ações de Albuquerque e do CBES. As tiragens do Boletim e do Jornal de Andrologia e a existência de um suposto gigantesco circuito jornalístico apresentam as mesmas características: divulgar números irreais de modo a impressionar leitores e editores. Pode-se presumir que Albuquerque tivesse agido da mesma forma com outras atividades e eventos do CBES?

É o próprio José de Albuquerque quem afirmava a existência de uma "Pinacoteca de Educação Sexual, sediada no CBES [...], com um acervo de 300 peças." (RIBEIRO; REIS, 2003). Em publicação de 1938, financiada com recursos próprios, Albuquerque afirmava que sua pinacoteca contava com 48 quadros, ainda que apenas 19 fossem de "grande formato". Possuíam descrições pomposas, que supostamente despertariam no visitante uma reflexão sobre a importância social da educação sexual. Por exemplo: "O indivíduo que foi esclarecido pela verdadeira luz da ciência sexual, não corre o risco de se deixar seduzir pelas vãs promessas de gozos sensuais." (ALBUQUERQUE, 1938b). A realidade de sua pinacoteca é difícil de ser avaliada, pois não parecem existir descrições 
independentes de seu acervo. Porém, há indícios de que Albuquerque tenha também inflado suas características.

Em finais dos anos 1930, o CBES passou a fazer suas conferências, bem como instalar a sua pinacoteca, no sobrado de um prédio à Rua do Rosário, 172, na cidade do Rio de Janeiro. Era um espaço bastante discreto, capaz de comportar cerca de 60 pessoas sentadas muito próximas entre si (PRÊMIO DE..., 1939, p. 1). Era ali, também, que Albuquerque recebia as mais diferentes visitas que procurava registrar em fotografias visando à divulgação em jornais e revistas. É apenas por estas fotografias, muitas de baixa qualidade, que se pode avaliar, mesmo que precariamente, o que seria a pinacoteca do CBES. Parecia ser composta de imagens das mais variadas qualidades, muitas delas não mais que ilustrações bastante simples, expostas às paredes. A maioria parece ser de cartazes, com temas muitas vezes ligados apenas marginalmente à questão sexual. Talvez o termo pinacoteca seja equivocado se tomado estritamente, pois grande parte não parece ser de pinturas. De toda forma, pela multidão de imagens, é possível que existissem, sim, 300 peças (para algumas das fotos a partir das quais este parágrafo foi escrito, ver CÍRCULO..., 1935b, p. 51; CÍRCULO..., 1935a, p. 14).

Menos referenciada nos estudos sobre José de Albuquerque é sua participação em programas radiofônicos, ainda que ele tenha afirmado que "[...] em possantes emissoras do Rio são feitas palestras sobre o assunto [educação sexual], continuamente." (EDUCAÇÃO..., 1943, p. 3).

Em 1934, durante a Semana da Educação Sexual no Rio de Janeiro, a Rádio Cajuti - estação da Tijuca inaugurada no ano anterior, de 500 Watts de potência (CASÉ, 1995, p. $133)^{12}$ - concedeu 10 minutos por dia de sua programação a Albuquerque. Participação que deve ter rendido interesse dos ouvintes pois, em novembro do mesmo ano, Albuquerque foi convidado a fazer uma série de 15 palestras, às quintas-feiras, às 19h. (O RÁDIO..., 1934, p. 12). Durante a Terceira Semana da Educação Sexual, em 1937, fez uma palestra individual na Rádio Ipanema. (TERCEIRA..., 1937, p. 12). Em setembro do ano seguinte Albuquerque buscou inaugurar, também na Rádio Ipanema, uma espécie de teatro-escola de educação sexual, com sketches sobre educação antivenérea. Em 10 de setembro de 1938 foi encenado "No consultório do Dr. Xizto [...] interpretado por destacados membros do CBES.” (DIA..., 1938, p. 10). Em março de 1940, ainda na Rádio Ipanema, apresentou algumas palestras (CÍRCULO..., 1940, p. 10), também tratando de temas genéricos ligados à educação sexual. Participações pontuais em diferentes emissoras, por conta de eventos específicos - como a exibição de filme sobre educação sexual, ou celebração de atividades ligadas ao dia do sexo ${ }^{13}$ - também ocorreram durante a década de 1930. Assim, suas participações radiofônicas existiram, mas foram esporádicas. 


\section{PERGUNTAS SEM RESPOSTA: OS TÍTULOS DE JOSÉ DE ALBUQUERQUE}

Em reportagem de 1943 afirmava-se que "[...] o dr. José de Albuquerque é um nome de projeção da sexologia mundial", pois pertenceria à "Soc. de Sexologia de Paris, à Soc. Médica de Valparaíso, à Soc. Mexicana de Eugenésia, presidente honorário de Comitê de Sexologia do $1^{\circ}$ Congresso Interamericano de Higiene Mental.” (EDUCAÇÃO..., 1943, p. 3). Palavras e títulos semelhantes que aparecem em obra publicada no mesmo ano, aos quais Albuquerque adicionava ser também delegado junto à Union Internationale contre le Peril Venérien, membro de honra estrangeiro do $1^{\circ}$ Congresso de Eugenia de Lima, membro honorário da $2^{\mathrm{a}}$ Jornada Peruana Antivenérea, membro honorário do $1^{\circ}$ Congresso de Medicina Interna do México, membro correspondente do Instituto Argentino de la Población. (ALBUQUERQUE, 1943, p. 21).

Tais títulos e participações em eventos, cuja única fonte de informação de que dispomos é o próprio José de Albuquerque, foram utilizados por pesquisadores de sua obra e dos trabalhos do CBES como demonstrações de que o reconhecimento internacional de seu trabalho fora significativo e, até mesmo, "espantoso" (MALCHER, 2007, p. 137). Chegou-se inclusive a considerar que Albuquerque teria sido mais prestigiado no exterior do que no Brasil. (CARRARA, 1996, p. 257; RUSSO; CARRARA, 2002). Não parece ter sido esse o caso. Porém, é fato ser difícil, na atualidade, possuirmos uma noção bastante exata do significado de seu currículo, ou mesmo qual seria, por assim dizer, sua precisão.

O primeiro problema é conseguirmos identificar, exatamente, qual a instituição a que Albuquerque originalmente se referia. Por exemplo, é apenas por exclusão que podemos considerar, com alguma convicção, que a Societé de Sexologie de Paris, da qual dizia participar, fosse aquela criada pelo médico francês Edouard Toulouse em 1932; neste caso, uma instituição de pouca representatividade e que teve existência efêmera. (CHAPERON, 2014, p. 142). No mesmo sentido, pode-se apenas conjecturar que o Instituto Argentino de la Población fosse aquele ligado ao Museu Social Argentino também de pouca expressividade.

Algo semelhante acontece em relação a eventos. O Primeiro Congresso Interamericano de Higiene Mental é facilmente identificável: ocorreu no Rio de Janeiro e em São Paulo, em 1936. (LUISI, 1950, p. 186). E, com quase toda certeza, o $1^{\circ}$ Congresso de Eugenia de Lima a que Albuquerque se refere teria sido, na verdade, a Primera Jornada Peruana de Eugenesia, ocorrida 1939 (PRIMEIRA..., 1939, p. 9): existem evidências bastante concretas de que Albuquerque participou desse congresso. Por outro lado, seria o Congresso de Medicina Interna do México, do qual ele teria sido escolhido membro honorário, aquele ocorrido no final de maio de 1942? (GLICK; RUIZ; PUIG-SAMPER, 1999. p. 191). Afinal, neste mesmo período, Albuquerque parecia estar atendendo em seu consultório e organizando uma conferência pelo CBES no Rio de Janeiro. (DOENÇAS..., 
1942, p. 4; A CONFERÊNCIA..., 1942, p. 10). Na verdade, é possível que Albuquerque utilizasse a expressão "membro honorário" como sinônimo para "não participante", pois algo semelhante acontece com a $2^{\mathrm{a}}$ Jornada Peruana Antivenérea: o referido congresso aconteceu nos dias 2 a 9 de dezembro de 1943, e José de Albuquerque parecia estar no Rio de Janeiro nesses dias ${ }^{14}$, inclusive realizando uma conferência com o título A educação sexual na puberdade no dia 2. (A CONFERÊNCIA..., 1943, p. 13). Os documentos relativos ao congresso, por sua vez, fazem referência às ideias de Albuquerque, mas o texto se refere à sua participação de 1939 (LULLI, 1944, p. 151). Ou seja, ao que parece Albuquerque inseria em seu currículo, sob o adjetivo "honorário", eventos dos quais não teria efetivamente participado. Seria por conta da liberdade que tomava em relação a esse adjetivo que não foi possível encontrar indícios de que tenha sido, como afirmou, presidente honorário do Primeiro Congresso Interamericano de Higiene Mental?

Outros problemas são os ligados à análise dos títulos. Se aceitarmos as explicações oriundas do próprio CBES, Albuquerque teria sido escolhido membro honorário da Sociedad Mexicana de Eugenesia "[...] em vista da alta representatividade cultural que lhe corresponde por seus méritos." (SOCIEDADE..., 1939, p. 5). Mas o que significaria, por outro lado, ter sido escolhido delegado da Union Internationale contre le Peril Venérien? Que condições ou exigências, além de obrigações, envolveriam ser presidente honorário de Comitê, membro de honra estrangeiro, membro correspondente das diversas instituições e eventos? Sua curta descrição sobre como se tornou membro da Sociedade Médica de Valparaíso, por exemplo, não transmite nenhuma ideia de oficialidade: “[...] numa convenção unânime de seus colegas chilenos, foi conferido ao Dr. José de Albuquerque o título de membro da Sociedade Médica de Valparaíso.” (PRIMEIRA..., 1939, p. 9).

E, finalmente: onde poderíamos encontrar documentos que comprovariam tais relações? Tais dúvidas são de difícil solução. Mas, ainda assim, das poucas certezas que foram possíveis de ser obtidas, é possível extrair algumas conclusões.

A participação de Albuquerque na Societé de Sexologie de Paris parece ter sido, ao menos para ele, significativa: fez questão de registrar o fato em 1936 em vários jornais cariocas, inseriu o título em seu currículo, além de adicionar, desde 1940, Membro da Sociedade de Sexologia de Paris aos anúncios de seu consultório que mandava publicar. Porém, como vimos, tratou-se de uma instituição de pouca representatividade e de existência bastante efêmera. E, na verdade, quaisquer pesquisas sobre a Societé de Sexologie de Paris (ou Sociedade de Sexologia de Paris) trarão como resultado, quase que exclusivamente, referências a trabalhos sobre o próprio José de Albuquerque. Teria sido ele o mais importante membro da organização? Não parece ter existido nenhum outro médico brasileiro que a conhecesse ou dela fizesse parte, ou nenhuma outra instituição que estivesse de alguma forma ligada a ela. 
De toda forma, analisando-se tanto sua produção bibliográfica quanto as citações a suas obras, além das participações em eventos, pode-se concluir que o reconhecimento internacional de Albuquerque realmente existiu, mas não foi muito significativo. Teve seu trabalho conhecido por alguns colegas estrangeiros, textos publicados em anais de congressos, e era eventualmente identificado como alguém de relevância no cenário da educação sexual no Brasil. Porém, referências ao trabalho de Albuquerque em outros países são escassas, e sua produção em língua estrangeira é muitíssimo menor. Não parece ser correto afirmar, portanto, que o reconhecimento de Albuquerque teria sido significativo fora do Brasil ${ }^{15}$ nem, muito menos, que fosse um "nome de projeção da sexologia mundial".

\section{ALBUQUERQUE, O RETRÓGRADO}

Os equívocos de julgamento em relação às análises do pensamento de José de Albuquerque não se encerram, porém, na aceitação dos números fantasiosos das ações do CBES. Estenderam-se para a interpretação de suas ideias, constantemente tomadas como exemplos de modernidade, igualdade de gêneros, confrontação ao conservadorismo (católico especialmente - mas não somente). Neste item pretendo apresentar exemplos da concepção retrógrada, inclusive para a época, das ideias de Albuquerque e, no item seguinte, discutir as possíveis razões para que seu pensamento tenha sido erroneamente classificado como modernizante ou liberal.

Inicialmente, eis a opinião de um resenhista que, em 1935, assistiu ao filme $A$ educação sexual nos diversos períodos da vida, o único que parece ter sido produzido pelo CBES:

Tal como o filme foi confeccionado parece que o erro é a regra geral, a doença o fantasma sempre presente, o que produzirá nas crianças e nos adolescentes uma penosa impressão, eivando de susto e desgosto a função genésica. (NUNES, 1935, p. 23).

Essa resenha sintetiza uma perspectiva comumente adotada por Albuquerque em seus artigos, palestras e cartazes: a luxúria destruindo a juventude; doenças venéreas representadas como serpentes ou dragões atacando o Brasil; o desejo sexual como um trem desgovernado; a lubricidade como perigo à espreita ${ }^{16}$. Enquanto as camadas médias e altas urbanas consumiam obras que apresentavam o ato sexual como sinônimo de prazer, seguindo uma tendência que havia se originado ainda nas últimas décadas do século XIX no pensamento sexológico, Albuquerque insistia em associar o ato sexual a medo, dor, doença, desprazer, perigo, destruição. "Segundo uma estatística por mim realizada, baseada num inquérito entre 5.000 indivíduos do sexo masculino" - creio que a esta altura do artigo temos o direito de questionar a existência dessa pesquisa - "[...] cheguei à conclusão de que mais de oitenta por cento da população masculina é vitimada pelas 
Artigo

doi: $10.20396 /$ rho.v18i3.8652134

doenças venéreas." (ALBUQUERQUE, 1935a, p. 4). Retornando a um imaginário que alcança o século XVIII, por conta da intensa preocupação com o aumento da urbanização e os problemas que os atos sexuais poderiam provocar, José de Albuquerque apresentava uma visão que culpabilizava o erotismo, depreciava o prazer erótico e fundamentava suas argumentações em princípios moralistas e religiosos. É bastante indicativo da forma que compreendia os atos e desejos sexuais o fato de afirmar, em 1935, que "[...] em matéria sexual, a sociedade de hoje apresenta o mesmo aspecto que apresentava na idade média", quando se aproveita da "[...] sexualidade pelo seu lado torpe, pelo seu lado licensioso e imoral” (ALBUQUERQUE, 1935c, p. 2).

Um exemplo seria o carnaval, “[...] festa de recalcados sexuais”, em que as pessoas “[...] colocam máscaras na face e tiram as máscaras da alma”. Se Albuquerque celebrava que as marchinhas de 1938 "[...] não apresentaram em suas letras [...] o requinte da malícia e a licenciosidade velada" dos anos anteriores, isso não alterava, porém, a condenável sensualidade das danças nos salões:

Nos bailes, não dançavam ao som das músicas [...]; o que a quase totalidade fazia era gingar o corpo em meneios provocadores procurando tocar as partes pudendas dos corpos das pessoas de outro sexo e alguns até do mesmo sexo (ALBUQUERQUE, 1938c, p. 3).

Pode-se encontrar em Albuquerque discursos inflamados condenando "o povo" que, sem marchinhas de carnaval com letras maliciosas, "[...] alterou a seu bel-prazer a letra de muitas delas para lhes dar o sentido que sua licenciosidade recalcada queria"; contra livros de educação sexual que nada mais seriam do que "[...] abomináveis repositórios da mais baixa e asquerosa imoralidade" (ALBUQUERQUE, 1934a, p. 3); ou contra o desrespeito aos imperativos biológicos que "[...] leva os indivíduos a consequências [...] irreparáveis e funestas, porque divorciadas das verdadeiras prescrições da ética sexual." (ALBUQUERQUE, 1934b, p. 3). Declarações que carregam um nítido desconforto em relação à sensualidade e ao erotismo. Além disso, termos como luxúria, concupiscência, lubricidade, licenciosidade, imoralidade, tão fartamente usados por Albuquerque, eram comuns no vocabulário de textos de fundo religioso que tratavam da questão sexual.

Mais ou menos explícitas nestas e em outras falas está uma visão cristã de condenação ao prazer sensual, embora disfarçada de discurso científico e respeito à biologia. Albuquerque censurava todo aquele que "[...] incutia [nos homens] que a função sexual é fonte de prazer." (ALBUQUERQUE, 1930, p. 139-40). E, na verdade, seria fundamental que pais e mestres "[...] não concorram para criar na mentalidade infantil o falso conceito de que a função sexual é uma função de prazer” (ALBUQUERQUE, 1934c, p. 1), pois o verdadeiro papel do ato sexual deveria ser pensado em função do fortalecimento familiar. Afinal, a família não era “[...] uma criação arbitrária dos homens", mas "[...] criação divina [...] que liga o indivíduo de um sexo ao de outro e ambos às 
pessoas dos filhos." (ALBUQUERQUE, 1938a, p. 3). O sexo, para José de Albuquerque, era pensado em termos quase vitorianos de redução do prazer, além da valorização da maternidade e da "[...] sacrossanta procriação" (ALBUQUERQUE, 1940b, p. 4): estaria nesses valores a realização do adequado "[...] trabalho que cabe a cada um na obra da criação" (ALBUQUERQUE, 1935c, p. 40). Desrespeitado o objetivo primeiro da procriação, o desejo sexual encaminharia os indivíduos a “[...] práticas antinaturais, que lhe acarretarão desequilíbrios gerais no organismo, privando-o dos benefícios da função e transformando-a em fonte de intermináveis malefícios." (ALBUQUERQUE, 1940a, p. $19)^{17}$.

O próprio Albuquerque sintetizou bem a relação que esperava conseguir entre educação sexual e sociedade:

[...] a educação sexual concorre para a maior estabilidade da família; defende o pudor das crianças, das moças e das senhoras; aprimora o sentimento religioso; e combate a lubricidade e a concupiscência. (ALBUQUERQUE, 1935b, p. 12).

É a partir de princípios de negação da validade do prazer sexual, valorização da família, centralidade religiosa da procriação, que Albuquerque resolvia possíveis contradições em seu pensamento. Está correto dizer, como já afirmaram outros pesquisadores (GOMES, 2017; CARRARA, 1996), que Albuquerque era contrário à abstinência sexual, pois argumentava que a prática violava princípios biológicos do desejo sexual. Mas, reforçando claramente sua visão condenatória ao prazer, Albuquerque era plenamente a favor da prima radical da abstinência, a castidade, verdadeira "[...] porta aberta que leva o indivíduo ao seu mais alto grau de aperfeiçoamento":

Com a castidade torna-se não só o homem como a mulher um ser perfeitamente equilibrado no físico, na mente e no sentimento. A castidade é o antídoto da luxúria. E qual o meio que temos para chegar à castidade afastando de nós esta luxúria? Não a educação calcada no empirismo, mas sim a que se inspira na ciência e estudo dos fatos sociais. (ALBUQUERQUE, 1939, p. 7).

Ciência como fundamento da castidade; castidade como auge do espírito humano e "antídoto da luxúria"; educação sexual que fomenta a perfeição sem sexo: sob a fina camada de apelo à cientificidade, à biologia, à neutralidade, estava uma estrutura conservadora e de negação do prazer. Quando propunha a educação sexual para homens e mulheres, não estava pensando em igualdade de gêneros, mas em construir um modelo de ensino que controlasse também o desejo feminino em função da procriação.

O Brasil dos anos 1930 e 40 era conservador, sem dúvida. Mas, Albuquerque o era ainda mais. Um homem à retaguarda de seu tempo, retrógrado em um contexto de desenvolvimento da valorização do prazer sexual. E isso pode ser explicitado de uma forma mais objetiva. $\mathrm{O}$ que estava sendo lido, à época, pelas classes média e alta das principais cidades do Brasil, sobre o ato sexual? Autores como o holandês Theodoor van 
de Velde (1933) e o alemão Fritz Kahn (1940). O matrimônio perfeito do primeiro, e Nossa vida sexual do segundo se tornaram best-sellers no Brasil, e estiveram à venda nas livrarias nacionais por décadas ${ }^{18}$.

Em suas obras, estes autores valorizavam o sexo pelo prazer que proporcionava: desde o início da vida conjugal, marido e esposa deveriam aprender a se conhecer mutuamente e descobrir como receber e dar prazer ao cônjuge, sendo o marido o professor e condutor da esposa. Prazer é, aqui, a palavra chave e o orgasmo (prioritariamente o simultâneo, considerado ideal) o objetivo final: confissão de amor, realização da biologia e, mesmo, expressão suprema de humanidade. E por ecoarem expectativas da sociedade em relação às questões sexuais, os livros de Velde e Kahn foram comprados e lidos, novas edições impressas, seu conteúdo se tornou socialmente disponível. A sociedade brasileira do período explicitou suas ideias sobre os temas sexuais adquirindo obras que estavam de acordo com sua concepção, e rejeitou aquele discurso que defendia o combate à "lubricidade e a concupiscência", que se centrava em doenças venéreas, que valorizava a castidade, e que alardeava os perigos da luxúria em uma explícita condenação ao prazer sexual.

É significativo que tendo seu Catecismo da educação sexual publicado na mesma editora - a Civilização Brasileira - e na mesma coleção - Biblioteca de Educação Sexual -, que os livros de Velde e Kahn, o livro de Albuquerque jamais alcançou uma segunda edição, e suas vendas foram tão limitadas que hoje se tornou item de colecionador. Moralizantes, as concepções de Albuquerque eram, na verdade, caracterizadas por um rígido princípio de diferença de gêneros fundado em um posicionamento de fundo religioso e rebaixamento do prazer. Não é à toa que classificava a própria atuação na divulgação sexual enquanto uma "cruzada", e deu o título de "catecismo" a um de seus livros.

\section{PRINCÍPIOS EQUIVOCADOS}

Porém, como os pesquisadores em história da educação sexual chegaram a concluir estarem diante de um modernizador reformista, quiçá revolucionário, da educação sexual no Brasil? Talvez o desejo inconsciente por um herói anti-obscurantismo tenha desempenhado algum papel: a crença de que apenas um iluminista seria capaz de tal impacto nas discussões sobre educação sexual no Brasil da época.

$\mathrm{Na}$ verdade, a forma de escrita de Albuquerque facilita a construção dessa interpretação. A leitura de seus artigos é tediosa, pois varia muito pouco em seus temas: há o constante apelo ao fim dos preconceitos sobre a educação sexual, afirmações recorrentes de que sexualidade não era imoralidade, pregações da prevalência da ciência na educação sexual. Os títulos se modificam, seu conteúdo se repete. 
O problema é que os apelos à ciência e à moralidade da questão sexual, além das condenações aos preconceitos por parte de Albuquerque foram lidos e interpretados pelos pesquisadores de maneira anacrônica: acreditaram encontrar ali significados atuais, projetando suas próprias noções de cientificidade e de combate ao preconceito. Porém, em Albuquerque, os significados eram outros: para ele, a educação sexual deveria ser discutida para que a verdadeira função do sexo, voltada à "sacrossanta procriação", pudesse enfim ser atingida. É isso o que, para ele, era "científico": uma educação sexual que reduzisse o prazer a uma questão secundária e favorecesse o que a biologia e a própria criação teriam definido como verdadeiro objetivo do desejo sexual, ou seja, a atração entre homens e mulheres com fim à reprodução. Caso contrário, teríamos práticas antinaturais e, daí, decadência moral e doenças venéreas. O próprio Albuquerque deixava claros os limites de seu modelo de educação sexual:

Mas, é preciso que ao se pretender educar o povo neste assunto, não se vá além do que se lhe convém ensinar, como via de regra sucede, porque ao em vez de se promover seu benefício, ir-se-ia indiretamente concorrer pra se lhe criar uma situação muito mais grave, sob muitos pontos de vista. (ALBUQUERQUE, 1935a, p. 4).

Eufemismos, digressões, e indiretas estão no centro do discurso de Albuquerque, notadamente nos artigos de jornais. Mas fica clara a ideia: não se pode ensinar demais, caso contrário, o povo aprenderá o que não se deve. Desvirtuará os adequados princípios "científicos" ligados à sua visão de ato sexual. Pensará o sexo pelo prazer, quando seu único objetivo é a reprodução como a natureza, portanto a biologia, ditou.

Além disso, a cientificidade de José de Albuquerque é autodeclarada. É ele quem se define científico, neutro, não preconceituoso. Mas em seus textos, o apelo à ciência é imediatamente seguido pela defesa de princípios fundados na moral. E é curioso observar como os conflitos com certos católicos (críticas ao trabalho do CBES em periódicos católicos, e veto à participação de Albuquerque em programas radiofônicos católicos) foram tomados, por pesquisadores da atualidade, por exemplos da modernidade do pensamento de José de Albuquerque. O problema é que nem todo conflito com o posicionamento da Igreja é de natureza inquisitorial, e tampouco cabe bem a Albuquerque o papel de Galileu. O conservadorismo não é monolítico, e suas diferentes correntes de posicionamento podem entrar em confronto. Foi exatamente este o caso de Albuquerque $v s$. determinados representantes do pensamento católico.

Não se pode esquecer que é possível ser transgressor sem atentar ao status quo. $\mathrm{Na}$ verdade, pode-se ser transgressor reforçando o status quo: Albuquerque se atreveu a falar de sexo e educação sexual em espaços públicos nos quais esses temas, usualmente, não estavam presentes. Mas, em seu pequeno palco, utilizou-se do microfone para reforçar os modelos sociais e de gênero existentes. 
Além disso, os posicionamentos da Igreja Católica eram importantes, mas estavam longe de determinar tendências comportamentais, também no campo sexual. Comparativamente bem mais significativo que os pontuais conflitos de Albuquerque com católicos, foi o caso de Theodoor van de Velde que teve sua obra incluída no Index de livros proibidos pela Igreja Católica, e chegou a ser citado de forma pejorativa pelo próprio papa. O livro não foi proibido por ser revolucionário: mas, como ocorrera com os textos de Albuquerque, por ser contra "[...] o recato e o pudor." (A CIÊNCIA..., 1933, p. 4). Explicitar as relações sexuais dentro da conjugalidade era visto pelos católicos como desrespeitoso à sacralidade conjugal. O mais importante é que essa explícita condenação papal não influenciou as vendas do livro de Velde, mesmo no maior país católico do mundo.

Por fim, educação sexual não é um valor em si a tal ponto que sua simples enunciação implique em transformação ou progresso social. Em primeiro lugar porque, como vimos ser o caso de Albuquerque, ela pode ser pensada em termos de restrição de opções, de inculcação do medo ou da vergonha, da imposição de certa moral sobre atos e desejos. Mas também porque o ato sexual, desejado ou praticado, é uma medida muito pobre de liberdade. Não se pode avaliar a igualdade de gêneros, por exemplo, pelo prazer sexual. Liberdade de ação social, nível de autodeterminação, igualdade de oportunidades em uma sociedade, não são medidas por orgasmos. Existiram sociedades como a chinesa antiga ou a islâmica medieval em que o prazer feminino era firmemente incentivado, com manuais que procuravam ensinar como os maridos deveriam produzi-lo em suas esposas, mas apenas enquanto parte da manutenção da estrutura social e subjugação feminina.

Tratava-se, assim, de uma educação sexual repressiva. Há certa transgressão em Albuquerque, mas não a defesa da autonomia dos indivíduos sobre seus corpos. Existe apenas a explicitação do ato sexual, em função de objetivos conservadores.

\section{CONCLUSÕES}

Em julho de 1933 ocorreu no salão nobre da Associação Brasileira de Imprensa a solenidade de posse do Círculo Brasileiro de Educação Sexual, com a presença de pelo menos 140 pessoas. (NO SALÃO..., 1933, p. 41). Pouco mais de um ano depois, um lotado salão de conferências do Liceu de Artes e Ofícios acompanhou o lançamento do "Curso Popular de Sexologia", também pelo CBES. Eventualmente, tais sucessos de público se repetiriam, como nas semanas da Educação Sexual no Rio de Janeiro e em São Paulo, ou na exibição do primeiro filme brasileiro de sexologia, no cine Broadway, no Rio de Janeiro, em 1935. (UM FILM..., 1935, p. 9). Durante aquela década, José de Albuquerque ainda conseguiu fazer com que alguns jornais do Rio de Janeiro (especialmente Jornal do Brasil, Diário Carioca, A Batalha, A Noite) mantivessem o público informado, a partir de pequenas notas, sobre $\mathrm{o}$ andamento das atividades do CBES. 
Porém, nem sempre foi assim. Em boa parte do tempo o CBES lutava para manter alguma atenção pública: seus livros tinham vendas discretas, seu Boletim tiragens limitadas, seus artigos eram reproduzidos apenas marginalmente, suas participações no rádio, esporádicas. E, em seus esforços para se manter em evidência, o eterno presidente do Círculo, José de Albuquerque, tomou como ação estratégica recorrente a de inflar, por vezes para além dos limites do absurdo, suas ações e conquistas. Diante da mescla de verdades e mentiras, parece ter sido uma constante que por detrás de uma suposta fabulosa ação, estupenda tiragem, sensacional reconhecimento, houvesse práticas limitadas, textos pouco lidos, públicos restritos.

Falou-se muito aqui de José de Albuquerque. Mas quero deixar o mais evidente possível, caso ainda não tenha ficado claro, que este artigo não é sobre ele. Albuquerque nada mais fez que buscar divulgar um trabalho e as ideias nos quais acreditava. É bem verdade que, muitas vezes, usando o método Munchausen. Seus exageros, a princípio, não prejudicaram ninguém (não, pelo menos, à época), e tiveram como razão última objetivos que ele entendia como médicos e mesmo patrióticos. Talvez haja algum maquiavelismo nessa interpretação; mas se houver, ela é inofensiva. Afinal, se o fim dos projetos do CBES fosse o lucro, Albuquerque teria melhores formas de obtê-lo: poderia ter aproveitado alguns momentos de maior visibilidade e adaptar suas ideias àquilo que a audiência da época esperava. Mas ele jamais o fez. Sua coerência o manteve fiel a certas concepções ultrapassadas e rejeitadas pela opinião pública. Certamente Albuquerque investiu muito do próprio dinheiro na manutenção do CBES. E não tenho dúvidas de que externava o resultado de certas experiências particulares quando afirmou, no prefácio que escreveu à obra de Velde, que "[...] o inexperiente no comércio de livros pensa que o que leva os editores a aumentar a produção de seus livros de sexologia seja a ânsia do lucro [...] Ledo engano!" (ALBUQUERQUE, 1957, p. 7).

Albuquerque não tem qualquer responsabilidade naquilo que foi transformado, desde o final do século XX. E esse é o ponto crucial. Teria ele gostado desse patamar que lhe fora concedido pelos pesquisadores em história da educação sexual? Não sei dizer. Mas o fato é que o campeão multimidiático da educação sexual, iluminista do sexo, cientista objetivo e não moralista, que causara tamanho rebuliço nos anos 1930 com suas ideias polêmicas no Brasil e no exterior, e cujos defeitos eram pontuais e negligenciáveis - esse personagem não existe. Ou melhor: existe apenas nas páginas daqueles que, usando aproximadamente as mesmas fontes e citando-se mutuamente, acabaram por inventá-lo, em desrespeito às evidências e a algumas das mais básicas normas da metodologia histórica.

Não se deve cair no julgamento oposto, porém; temos condições de sermos melhores do que construir visões dicotômicas e absolutas da realidade. O trabalho de José de Albuquerque teve alguma visibilidade, especialmente na cidade do Rio de Janeiro e municípios vizinhos; foi sim um pioneiro das discussões sobre educação sexual, ainda que fundado em ideias ultrapassadas para o próprio período, bem expressas em seu Boletim que 
tinha, aliás, pequena circulação; lutou praticamente sozinho para a manutenção e expansão do CBES com resultados limitados, ainda que certos eventos tenham apresentado algum sucesso; construiu certa reputação que se esvaiu rapidamente, mas que em dado momento foi suficiente para que encontrasse público para palestras em alguns locais do Brasil.

Mas seu impacto não se estendeu para muito além do momento de suas conferências, das notinhas nos jornais, da leitura de seu boletim. Os debates que gerou, ou nos quais fora envolvido, tiveram existência efêmera. Não deixou filosofia nem discípulos. E é assim que se pode responder à questão do resenhista citado na introdução deste artigo: por que, enfim, teria José de Albuquerque ficado no esquecimento por décadas?

Porque seu trabalho foi esquecível. Porque suas ações não encontraram repercussão profunda na sociedade do período, fluminense ou brasileira, justamente porque expressava ideias que nos anos 1930 e 40 eram vistas como ultrapassadas. A suposta modernidade de um projeto de "educação sexual para as massas" era acompanhado de um discurso moralista, retrógrado, superado. As pequenas transgressões de Albuquerque de vir a público falar de sexo chamavam a atenção, mas suas ideias não ecoavam na elite de classe média alta urbana e letrada, que preferia textos bem mais favoráveis à relação entre desejo, sexo e conjugalidade.

O mistério, portanto, não está no esquecimento de Albuquerque por tantas décadas. Está em descobrir por que, desde o final do século XX, pesquisadores em história da educação sexual passaram a celebrá-lo como campeão multimidiático e herói do liberalismo sexual, contrariando as mais óbvias evidências documentais.

Explicitados os exageros, o que resta a dizer sobre os trabalhos acadêmicos que se fundamentaram em tais dados equivocados a respeito de José de Albuquerque?

Devem necessariamente ter suas conclusões reavaliadas. Partiram do pressuposto de que Albuquerque fosse uma espécie de Lutero da educação sexual, e que as teses de seu boletim tivessem ecoado pela sociedade brasileira dos anos 1930. Quando, na verdade, a influência de seu pensamento é mais comparável à de um Menocchio (GINZBURG, 1987), ou não muito longe disso: eventualmente interessantes, na maior parte do tempo excêntricas, e rapidamente esquecidas. Para que se realize uma efetiva análise histórica, feita por historiadores ou não, o impacto e a divulgação social de uma ideia são essenciais. Se tivesse seus artigos publicados mais de 100 mil vezes, seu pensamento seria eco da sociedade do período. Mas seus poucos sucessos foram esporádicos e os estudos sobre seu pensamento devem considerar essa limitada influência.

Em história, é bastante difícil comprovar que algo não aconteceu. $O$ que usualmente se pode é argumentar o quão improvável teria sido a ocorrência de certo evento ou processo (FONTOURA, 2017). No caso estudado neste artigo, todos os documentos históricos convergem para a mesma conclusão: a de que Albuquerque inflou, a níveis absurdos, suas ações. E é provável que tenha simplesmente inventado outras - caso da 
pesquisa científica com cinco mil indivíduos ou da publicação poliglota do Jornal de Andrologia.

Ao que parece, muitos pesquisadores ficaram encantados quando se depararam, a partir do que dizia o próprio José de Albuquerque, com as supostas fabulosas conquistas alcançadas pelo Círculo Brasileiro de Educação Sexual. Porém, como já dizia Carl Sagan, afirmações extraordinárias demandam provas extraordinárias: o adequado procedimento histórico exigiria que aquelas afirmações fossem confrontadas a outras fontes. Sucumbir ao "[...] primeiro impulso natural [que] nos leva a aceitar como verdadeiras todas as afirmações contidas em um documento" (LANGLOIS; SEIGNOBOS, 2014, tradução nossa) é um erro que Langlois e Seignobos acreditavam ser importante ensinar a seus alunos no século XIX, e que muitos pensavam já não fosse mais necessário dizer.

\section{REFERÊNCIAS}

A CIÊNCIA ao serviço da corrupção em torno da educação sexual. A Cruz, Rio de Janeiro, p. 4, 29 out. 1933.

A CONFERÊNCIA de hoje do Dr. José de Albuquerque. A Noite, Rio de Janeiro, p. 10, 2 jun. 1942.

A CONFERÊNCIA de hoje do Dr. José de Albuquerque. A Noite, Rio de Janeiro, p. 13, 8 dez. 1943.

A NOITE ilustrada. A Noite. Rio de Janeiro, p. 2, 6 dez. 1934.

A PROGRESSÃO da venda de A Noite. A Noite, Rio de Janeiro, p. 1, 15 jun. 1931.

ALBUQUERQUE, J. Catecismo da educação sexual. Rio de Janeiro: Civilização Brasileira, 1940a.

ALBUQUERQUE, J. Como estudar sexologia? O operário, Montes Claros, MG, p. 3, 15 de janeiro de 1934a.

ALBUQUeRQUe, J. Continência e castidade. Correio do Paraná, Curitiba, p. 7, 23 fev. 1939.

ALBUQUERQUE, J. Educação sexual e doenças venéreas. Jornal do Commercio, Campo Grande, MT, p. 4, 23 mar. 1935a.

ALBUQUERQUE, J. Educação sexual pelo rádio. Rio de Janeiro: Círculo Brasileiro de Educação Sexual, 1935b.

ALBUQUERQUE, J. Herança e educação. A Época, Caxias, RS, p. 4, 12 maio 1940b. 
ALBUQUERQUE, J. Moral sexual. Rio de Janeiro: Typ. Coelho, 1930.

ALBUQUERQUE, J. O perigo venéreo na paz, na guerra e no após-guerra. Rio de Janeiro: Freitas Bastos, 1943.

ALBUQUERQUE, J. Os problemas sexuais e o comunismo. O Município, Rio Preto, MG, p. 3, 3 abr. 1938a.

ALBUQUERQUE, J. Perigos sexuais. Alto S. Francisco, Alto S. Francisco, MG, p. 3, 25 nov. 1934b.

ALBUQUERQUE, J. Pinacotheca de educação sexual. Rio de Janeiro: Rodrigues \& Cia, $1938 b$.

ALBUQUERQUE, J. Prefácio. In: VELDE, T. O matrimônio perfeito. Rio de Janeiro: Civilização brasileira, 1957.

ALBUQUERQUE, J. Quatro letras, cinco lustros. Rio de Janeiro: Jornal do Comércio, 1958.

ALBUQUERQUE, J. Quem deve ministrar educação sexual às crianças? O Combate, São Luís, MA, p. 1, 15 fev. 1934c.

ALBUQUERQUE, J. Redenção sexual. O Combate, Fortaleza, CE, p. 2, 5 maio 1935c.

ALBUQUERQUE, J. Sexo e carnaval. Gazeta de Tombos, Tombos, MG, p. 3, 26 mar. 1938c.

ALMANAK LAEMMERT. Anuário comercial, industrial, profissional, administrativo, de estatística e informações gerais do Brasil. Rio de Janeiro: Laemmert, 1934.

AUGUSTO, V. Uma contribuição à historiografia da educação sexual no Brasil. Araraquara, SP: Ed. da UNESP, 2015.

BARBOSA, M. História cultural da imprensa. Rio de Janeiro: Mauad X, 2007.

BESSE, S. Freedom and Bondage. United States: Yale Univerity, 1983.

CARRARA, S. Tributo a Vênus. Rio de Janeiro: Fiocruz, 1996.

CARTAZES de propaganda cívica. A Noite, Rio de Janeiro, p. 5, 2 out. 1937.

CASÉ, R. Programa Casé: o rádio começou aqui. Rio de Janeiro: Mauad, 1995.

CHAPERON, S. The Revival of Sexuality Studies in France in the Late 1950s. In.

HEKMA, G.; GIAMI, A. Sexual revolutions. Reino Unido: Palgrave, 2014.

CÍRCULO brasileiro de educação sexual. A Reforma, Tarauacá, AC, p. 4, 25 fev. 1934. 
CÍRCULO brasileiro de Educação Sexual. Jornal do Brasil, Rio de Janeiro, p. 10, 8 mar. 1940.

CÍRCULO brasileiro de Educação Sexual. Revista da Semana, Rio de Janeiro, p. 14, 12 out. 1935a.

CÍRCULO brasileiro de Educação Sexual. Revista da Semana, Rio de Janeiro, p. 51, 7 set. $1935 b$.

CÍRCULO brasileiro de Educação Sexual. Revista Suburbana, Rio de Janeiro, p. 5, 1 jul. 1933.

DIA anti-venéreo. Jornal do Brasil, Rio de Janeiro, p. 10, 10 set. 1938.

DINIZ, S. Gênero e educação sexual no Correio Oficial de Goiás na década de 30.

Goiânia: Ed. da UFG, s/d. Disponível em <https://pos.historia.ufg.br/up/113/o/S\%

C3\%A1via_Barros_Diniz.pdf>. Acesso em: 12 mar. 2018.

DOENÇAS sexuais do homem. A Noite, Rio de Janeiro, p. 4, 30 maio 1942.

EDUCAÇÃO sexual no Brasil: palestra com o Dr. José Albuquerque, eminente sexologista. O Dia, Curitiba, p. 3, 13 out. 1943.

FELICIO, L. A. A moralização do sexo: os debates sobre a educação sexual para o Projeto de Nação Brasileira na I Conferência Nacional de Educação, 1927. 2012. 155 f. Dissertação (Mestrado em História das Ciências e da Saúde) - Fundação Oswaldo Cruz, Casa Oswaldo Cruz, Rio de Janeiro, 2012.

FONTOURA, A. Teoria da história. Curitiba: Intersaberes, 2017.

GINZBURG, C. O queijo e os vermes. São Paulo: Companhia das Letras, 1987.

GLICK, T.; RUIZ, R.; PUIG-SAMPER, A. (Ed.). El darwinismo en España e Iberoamérica. España: Ediciones Doce Calles, 1999.

GOMES, R. Meu encontro com os outros: memórias de José de Albuquerque, pioneiro da sexologia no Brasil. Cad. Saúde Pública, Rio de Janeiro, v. 33, n. 9, 2017. Resenha.

IMPOTÊNCIA em moço. Diário de Notícias, Rio de Janeiro, p. 6, 30 ago. 1933.

JORNAIS e revistas. A Noite, Rio de Janeiro, p. 8, 21 jan. 1931.

JORNAL das moças. A Noite, Rio de Janeiro, p. 2, 4 maio 1932.

KAHN, F. Nossa vida sexual. Rio de Janeiro: Civilização brasileira, 1940. 
Artigo

doi: $10.20396 /$ rho.v18i3.8652134

LANGLOIS, C.; SEIGNOBOS, C. Introduction aux études historiques. Lyon, FR: ENS Éditions, 2014. Disponível em: <http://books.openedition.org/enseditions/273>. Acesso em: 12 jan. 2014.

LUISI, P. Pedagogia e conducta sexual. Uruguai: El siglo ilustrado, 1950.

LULLI, E. Segunda Jornada peruana antivenérea: Lima, 2-9 do diciembre de 1943.

Peru: Liga nacional de higiene y profilaxia social, 1944.

MAJESTOSO! Edificante! Soberbo! A Noite, Rio de Janeiro, p. 4, 31 jul. de 1935.

MALCHER, L. F. S. Aos cuidados de príapo: impotência sexual masculina, medicalização e tecnologia do corpo na medicina do Brasil. 2007. 196 f. Tese (Doutorado) - Universidade Federal do Rio Grande do Sul, Porto Alegre, 2007.

MARQUES, F. Editora Fiocruz lança autobiografia inédita de um pioneiro da sexologia no Brasil. Disponível em: <https://portal.fiocruz.br/livro/meu-encontro-com-osoutros-memorias-de-jose-de-albuquerque-pioneiro-da-sexologia-no-brasil >. Acesso em: 14 mar. 2016.

MIKOS, C. M. F. Produzir o sexo verdadeiro, regular o sexo educado: aproximações entre o cinema pornô e a educação sexual. 2017. 156 f. Dissertação (Mestrado em Educação) - Universidade Federal do Paraná, Curitiba, 2017.

NO SALÃO nobre... Fon-fon, Rio de Janeiro, p. 41, 5 ago. 1933.

NUNES, M. Os filmes que fomos ver. Jornal do Brasil, Rio de Janeiro, p. 23, 25 jun. 1935.

O RÁDIO a serviço da educação sexual. Jornal do Brasil, Rio de Janeiro, p. 12, 15 nov. 1934.

OS CORRUPTORES. O Commercio, Patrocínio, MG, p. 1, 29 abr. 1934.

PARA o melhor livro sobre educação sexual. Diário carioca, Rio de Janeiro, p. 10, 3 mar. 1937.

PELO BRASIL. O Lar Católico, Juiz de Fora, MG, p. 4, 29 out. 1933.

PERISSE, J. Vida odontológica. Gazeta de Notícias, Rio de Janeiro, p. 3, 3 ago. 1930.

PRÊMIO DE educação sexual. Beira-Mar, Rio de Janeiro, p. 1, 23 set. 1939.

PRÊMIO JOSÉ de Albuquerque. A Nação, Rio de Janeiro. p. 5, 12 jan. 1936.

PRIMEIRA jornada Peruana de Eugenesia. Jornal do Brasil, Rio de Janeiro, p. 9, 26 maio 1939. 
PROPAGANDA nos envelopes postais. A Noite, Rio de Janeiro, p. 18, 4 fev. 1937.

REIS, G. V. dos. Sexologia e educação sexual no Brasil nas décadas de 1920 - 1950: um estudo sobre a obra de José de Albuquerque. 2006. 92 f. Dissertação (Mestrado em Educação) - Universidade Estadual Paulista "Júlio de Mesquita Filho", Araraquara, 2006.

RIBEIRO, P. R.; REIS, G. V. José de Albuquerque e a educação sexual nas primeiras décadas de 1920-1950: um estudo bibliográfico. In: REUNIÃO ANUAL DA ANPED, 26., 2003, Poços de Caldas. Anais... Poços de Caldas, MG: Associação Nacional de PósGraduação e Pesquisa em Educação, 2003. p. 1-6. Disponível em: <26reuniao.anped.org.br/posteres/paulorennesribeiro.rtf>. Acesso em: 12 jan. 2015.

ROHDEN, F. Capturados pelo sexo. Ciênc. Saúde Coletiva, Rio de Janeiro, v. 17, n. 10, p. 2645-2654, out. 2012.

RUSSO, J.; CARRARA, S. A psicanálise e a sexologia no Rio de Janeiro de entreguerras: entre a ciência e a auto-ajuda. História, Ciências, Saúde, Rio de Janeiro, v. 9, n. 2, p. 273 290. maio/ago. 2002.

SCHEFFER. M.; BIANCARELLI, A.; CASSENOTE, A. (Org.) Demografia médica no Brasil. São Paulo: Conselho Regional de Medicina do Estado de São Paulo e Conselho Federal de Medicina, 2011. 1 v.

SILVA, E. A. da. Filosofia, educação e educação sexual: matrizes filosóficas e determinações pedagófgicas do pensamento de Freud, Reich e Foucault para a abordagem educacional da sexualidade humana. 2001. 287 f. Tese (Doutorado em Educação) Universidade Estadual de Campinas, Campinas, SP, 2001.

SOCIEDADE mexicana de Eugenesia. O Município, Rio Preto, MG, p. 5, 26 fev. 1939.

TERCEIRA semana de educação sexual. Jornal do Brasil, Rio de Janeiro, 9 jul. 1937.

UM FILM sobre educação sexual. Diário carioca, Rio de Janeiro, p. 9, 26 jun. 1935.

VELDE, T. O matrimônio perfeito. Rio de Janeiro: Civilização brasileira, 1933.

VIDAL, D. Educação sexual: produção de identidades de gênero na década de 1930. In. SOUSA, C.; MORAES, C. (Org.). Historia da educação: processos, práticas e saberes. São Paulo: Escrituras, 1998. p. 53-74.

\section{Notas}

\footnotetext{
${ }^{1}$ Universidade Federal do Paraná (UFPR). E-mail para contato: antoniofontourajr@ gmail.com

${ }^{2}$ Exemplos de trabalhos que citam a tiragem de 100 mil exemplares do Boletim: MALCHER, 2007; FELICIO, 2012; RIBEIRO, REIS, 2015; CARRARA, 2007; ROHDEN, 2012; MIKOS, 2017.
} 
${ }^{3} \mathrm{O}$ antropólogo Leonardo Malcher foi o único, que chegou a meu conhecimento, que se perguntou da origem dos recursos do CBES. Após afirmar que o Jornal de Andrologia circulava em cinco idiomas, era remetido a 18 mil médicos e a 2,5 mil hospitais, chegando atingir "surpreendentes" 30 mil exemplares em 1935 (dados extraídos do próprio jornal), Malcher pergunta: “A partir daí, cabe questionar: quem financiaria tudo isso?” A resposta que apresenta, porém, é insatisfatória e especulativa. "Pelo que pude constatar [...] havia uma relação com colaboradores, filiados que de certa forma deviam contribuir com as iniciativas do Círculo. [...] As outras iniciativas de Albuquerque [...] creio que conseguiam a colaboração de outros médicos e alguns políticos que se juntavam à causa". (MALCHER, 2007, p. 131-2) O autor, porém, não dá informações de quem seriam esses "outros médicos e alguns políticos", nem de onde teria extraído suas conclusões. De toda forma, essas soluções improvisadas não teriam condições de manter uma estrutura como a declarada por Albuquerque. Por fim, Malcher não questiona as tiragens ou outras supostas ações do CBES.

${ }^{4}$ Segundo uma nota de 1933 no jornal O Lar Católico, de Juiz de Fora (MG), "No Rio, funciona um 'Círculo Brasileiro de Educação Sexual' que está fazendo propaganda por meio de um boletim gratuitamente distribuído pelas caixas postais e pelos endereços tirados do catálogo de telefone” (PELO BRASIL, 1933, p. 4).

${ }^{5}$ Entre 2017 e 2018 os exemplares não poderiam ser consultados, pois estavam em fila para a restauração. Segundo o antropólogo Leonardo Malcher que os utilizou em sua pesquisa, já em 2007 as cópias estavam em péssimas condições: "No caso do Boletim de Educação Sexual [...], ele teve que ser manuseado num setor mais 'interno' da biblioteca, pois as condições de suas páginas eram lastimáveis. Mas, como algumas vezes parecia que estava mais fazendo um trabalho de arqueologia do que de antropologia, tinha que ter consciência, como os arqueólogos, de que o material que por nós é analisado, nunca é deixado como foi encontrado, mesmo que nosso cuidado seja o maior possível" (MALCHER, 2007, p. 42).

${ }^{6} \mathrm{O}$ termo "assinaturas" é particularmente estranho, afinal o boletim era distribuído gratuitamente; porém, além de existirem assinantes, Albuquerque afirma que as assinaturas deveriam ser renovadas anualmente (PRÊMIO JOSÉ DE ALBUQUERQUE, 1936, p. 5).

${ }^{7}$ De todos os artigos que encontrei, 66 deles foram publicados apenas uma vez, 9 por duas vezes, 3 por três vezes, e 3 por quatro vezes.

${ }^{8}$ Com uma alegada produção de um artigo por semana, tem-se 48 artigos por mês, entre 1934 e 1939 , totalizando 288 artigos; excluiu-se 1933, porque apenas a partir de dezembro daquele ano, como será visto a seguir, passou-se a ser afirmada a existência de um círculo de mais de 750 jornais. O cálculo acima se refere a publicações quinzenais (144 artigos, portanto).

9 A notícia (SC), Beira-mar (RJ), O estado (SC), O sol (MG).

${ }^{10}$ Este número se repetia em outras cartas. Um exemplar semelhante foi publicado no Correio Oficial de Goiás, de 20/12/1933, à página 8. (DINIZ, 2018, p. 7).

${ }^{11}$ Os "Armandos" seriam o secretário Armando da Silva Peixoto, e os membros do conselho consultivo Armando Carlos Alberto e Armando Cardoso Alberto ( sic).

${ }^{12}$ A potência da rádio seria suficiente, a princípio, para que Albuquerque fosse ouvido em boa parte da cidade do Rio de Janeiro.

${ }^{13}$ No qual, presumivelmente, em 1935, Albuquerque teria falado à Voz do Brasil (CARRARA, 1996, p. 268).

${ }^{14}$ Albuquerque tinha, por praxe, interromper os anúncios de seu consultório toda vez que deixava a cidade do Rio de Janeiro para viagens mais longas. Porém, no mês de dezembro de 1943 por apenas oito dias, e sempre em dias alternados, a propaganda não foi impressa no jornal A Noite.

${ }^{15}$ Não consegui encontrar qualquer indício que corroborasse a afirmação de que o Jornal de Andrologia fosse publicado em cinco idiomas. (MALCHER, 2007, p. 131).

${ }^{16}$ Pode-se encontrar a reprodução de alguns cartazes e ilustrações presentes no Boletim de Educação Sexual em Carrara, 1996.

${ }^{17}$ Entre as práticas antinaturais estavam, para Albuquerque, a homossexualidade (tanto a feminina quanto a masculina), a prática da sodomia, a masturbação, o sexo com animais, o "coito bucal". 
18 O Matrimônio Perfeito de Velde esteve à venda no Brasil até 1957; foi reeditado nos anos 1970 por um breve período, com o intuito de aproveitar a divulgação de um filme, de mesmo título, roteirizado pelo médico holandês. Nossa vida sexual, de Fritz Kahn, foi reeditado continuamente até a década de 1980.

Submetido em: 02/04/2018

Aprovado em: 17/07/2018

Publicado em: 28/09/2018 